\title{
Detection of SPG20 gene promoter-methylated DNA, as a novel epigenetic biomarker, in plasma for colorectal cancer diagnosis using the MethyLight method
}

\author{
NAYEBALI REZVANI ${ }^{1,2}$, REZA ALIBAKHSHI ${ }^{2}$, ASSAD VAISI-RAYGANI ${ }^{2-4}$, \\ HOMAYOON BASHIRI ${ }^{5}$ and MASSOUD SAIDIJAM ${ }^{1}$
}

\author{
${ }^{1}$ Research Center for Molecular Medicine, Hamadan University of Medical Sciences, Hamadan 6517838736; \\ ${ }^{2}$ Department of Clinical Biochemistry; ${ }^{3}$ Fertility and Infertility Research Center; ${ }^{4}$ Molecular Diagnostic Research Center; \\ ${ }^{5}$ Department of Gastroenterology, Kermanshah University of Medical Sciences, Kermanshah 6714869914, Iran
}

Received July 11, 2016; Accepted January 17, 2017

DOI: $10.3892 / 01.2017 .5815$

\begin{abstract}
Aberrant promoter methylation of genes is a common epigenetic alteration in colorectal cancer (CRC). In the present study, spastic paraplegia 20 (SPG20) promoter-methylated DNA, as a potential diagnostic biomarker, was investigated in plasma and tumor tissue samples from patients with CRC. To the best of our knowledge, the quantification of SPG20 promoter-methylated DNA in plasma samples remains unreported. SPG20 promoter methylation was investigated in 32 paired tumor and healthy adjacent tissues, 37 plasma samples from patients with CRC, and in 37 plasma samples from a healthy control group, using the MethyLight method. The percentage of methylated reference (PMR) values was determined for each sample, and the sensitivity and specificity of this unique biomarker were evaluated. PMR values were significantly higher in plasma samples from patients with CRC compared with in those from the control group $(\mathrm{P}<0.05)$. Plasma specimens from patients and healthy controls exhibited median PMR values of 7.7 (95\% CI, 4.15-15.28) and 0.59 (95\% CI, 0.14-1.12),
\end{abstract}

Correspondence to: Professor Massoud Saidijam, Research Center for Molecular Medicine, Hamadan University of Medical Sciences, Mahdiyeh Street, Hamadan 6517838736, Iran

E-mail:sjam110@yahoo.com

Abbreviations: SPG20, spastic paraplegia 20; CRC, colorectal cancer; CEA, carcinoembryonic antigen; EPD, eukaryotic promoter database; $\mathrm{T}_{\mathrm{m}}$, melting temperature; SEPT9, septin 9; CNRIP1, cannabinoid receptor interacting protein 1; FBN1, fibrillin 1; INA, internexin neuronal intermediate filament protein $\alpha$; MAL, mal, T-cell differentiation protein; SNCA, synuclein $\alpha$; FOBT, fecal occult blood test; ROC, receiver-operating characteristics; PMR, percent methylated reference; AUC, area under the ROC curve

Key words: colorectal neoplasms, methylation, epigenetic, biomarkers, spastic paraplegia 20, MethyLight method, plasma DNA, sensitivity, specificity, diagnostic respectively. Notably, the median PMR values were identified as 42.39 (95\% CI, 27.69-72.26) and 3.61 (95\% CI, 1.07-5.29) in tumor and adjacent healthy tissues, respectively. Using receiver-operating characteristics curve analysis, the area under curve (AUC) was demonstrated to be 0.984 for plasma samples, exhibiting a sensitivity of $81.1 \%$ and a specificity of 96.9\%. Furthermore, the AUC was 0.996 for tissue samples, revealing a sensitivity of $93.8 \%$ and specificity of $99.96 \%$. Results from the present study indicate that the identification of SPG20 promoter-methylated DNA in plasma is a potential diagnostic biomarker for the detection of CRC. Furthermore, the results demonstrate a satisfactory sensitivity and specificity, indicating the importance of SPG20 methylation as a novel noninvasive biomarker.

\section{Introduction}

Colorectal cancer (CRC) is one of the most common malignancies worldwide, accounting for an estimated 1.3 million new cases and $>500,000$ mortalities/year (1). CRC is the fourth leading cause of cancer-associated mortality worldwide, with a rapidly increasing incidence rate in the worldwide $(2,3)$. In the Asian population, the annual prevalence rate of $\mathrm{CRC}$ has steadily increased over the past two decades (4). The Ministry of Health and Medical Education in Iran states that cancer is the third most common cause of mortality in Iran (5). Currently, the gold standard method for CRC detection is internal imaging of the colon with colonoscopy followed by a biopsy examination; however, it remains an invasive procedure with possible serious complications and limitations (6). Cancer is a multistep process resulting from a gradual accumulation of genetic and epigenetic changes to the genome (7). The methylation of 5'-C-phosphate-G-3' (CpG) islands has been suggested to be associated with gene silencing, serving an important role in cancer development $(8,9)$. The aberrant promoter methylation of genes is a primary occurrence in the process of CRC carcinogenesis, which can be considered as a candidate diagnostic biomarker for CRC (10). A direct association between promoter methylation and cancer development has 
caused a growing interest in the use of plasma methylation as a diagnostic biomarker for patients with cancer (11). There are numerous reports of methylation biomarkers tested in fecal and plasma samples (12-15). Previous epigenomic studies have revealed that a number of genes, including spastic paraplegia 20 (SPG20), can potentially be silenced in patients with CRC due to DNA hypermethylation within promoter regions (16-19). This has prompted the opportunity to implement a reliable, inexpensive and simple approach for CRC detection $(16,17)$. The SPG20 gene is located in chromosome band 13q13.3; the SPG20 gene encodes the spartin protein, which is a multifunctional protein that has previously been identified to be involved in intracellular epidermal growth factor receptor trafficking (20), and in lipid droplet turnover (21). It has also been reported to be an inhibitor of bone morphogenetic protein (BMP) signaling (22) and an adaptor for E3 ubiquitin ligases (23). The spartin protein contains a Microtubule-Interacting and Trafficking molecule (MIT) domain in the N-terminus (24). It has also been demonstrated that there is a function for the spartin protein in cytokinesis (18). In a study performed by Connell et al (25), it was observed that the knockdown of SPG20 gene expression results in a cytokinesis arrest; however, the number of cells arrested in cytokinesis was decreased when the spartin protein was re-expressed. In a gene expression study using microarray analysis, when colon cancer cell lines were treated with 5-aza-2'deoxycytidine, it was demonstrated that SPG20 could be considered as a potential epigenetic biomarker for the diagnosis of CRC (18). As compared with mRNA expression, methylation studies on a variety of cancer cell lines have demonstrated that aberrant methylation of the SPG20 promoter is not only associated with gene silencing but also can subsequently cause a cytokinesis arrest and aneuploidy, a situation thought to be correlated with tumorigenesis (26). Early diagnosis of CRC can reduce mortality and improve the overall survival rate of patients with CRC. However, currently available diagnostic methods are limited by their invasiveness, or suboptimal sensitivities and specificities. Although colonoscopy is currently applied as a routine diagnostic method for CRC, its application is limited by low acceptability in a screening setting (6). As an available non-invasive method, fecal occult blood testing (FOBT) demonstrates no or low impact on CRC incidence because of its low sensitivity (27).

Currently, it is generally accepted that methylation markers may be suggested as reliable markers to effectively identify patients with CRC at earlier stages. Aberrant promoter methylation of genes is a common epigenetic alteration found in CRC, which can be detected in blood or stool samples (28). However, the quantification of SPG20 promoter-methylated DNA in plasma samples has not yet been reported. In the present study, the presence of SPG20 gene promoter-methylated DNA was measured in plasma and tissue samples from patients with CRC. The aim of the current study was to determine whether the quantity of circulating methylated DNA of the SPG20 gene could discriminate between patients with CRC and healthy individuals. In addition, the level of SPG20-methylated DNA in plasma samples was compared with a routine blood-based tumor marker, carcinoembryonic antigen (CEA), for the first time.

\section{Materials and methods}

Tissue and plasma samples. A total of 37 patients with CRC and 37 healthy individuals were included in the present study. The age range and gender distribution is summarized in Table I. However, it was not possible to collect tissue samples from 5/37 patients with CRC. A total of 32 paired tumor and adjacent healthy tissues were collected from the freshly resected colon tissue of patients with CRC who underwent an elective colon cancer surgery. Histological grading system was used for grades of malignancy of CRC based on the highest poorly differentiated clusters (29).

The present study was reviewed and approved by the Medical Faculty Ethics Committee of the University of Hamadan (reference no. 3482, 2014; Hamadan, Iran). All samples were collected from Bistoon Hospital (Kermanshah, Iran) from March to November 2016. Written informed consent was obtained from all participants. No patients had received chemotherapy or radiotherapy prior to the surgical procedure. Healthy subjects without any evidence of CRC following a colonoscopy were included as a control group. As illustrated in Table I, all patients and healthy individuals were matched for demographic variables.

Small tissue samples were immediately stored in liquid nitrogen for subsequent methylation assays, while other samples were fixed in formalin for the routine histological examination. Blood samples were obtained from 37 patients with CRC and 37 healthy individuals prior to surgery. For each subject, $5 \mathrm{ml}$ of blood was collected in an EDTA vacutainer tube. Plasma was isolated using centrifugation at 2,500 $\mathrm{x} g$ and $4^{\circ} \mathrm{C}$ for $15 \mathrm{~min}$. All samples were then transferred into polypropylene tubes and stored at $-80^{\circ} \mathrm{C}$ for use in subsequent experiments.

DNA extraction from tissue and plasma samples. Total genomic DNA was purified from $200 \mu \mathrm{l}$ plasma and $20 \mathrm{mg}$ tissue samples. The samples were dissolved in lysis buffer (Qiagen GmbH, Hilden, Germany) containing protease, followed by DNA extraction using a QIAamp DNA Blood Mini kit (Qiagen GmbH, Hilden, Germany; cat. no. 51104) according to the manufacturer's instructions. DNA concentration and purity were determined using a NanoDrop ND-1000 spectrophotometer (Thermo Fisher Scientific, Inc., Wilmington, DE, USA). Purified DNA was eluted in buffer $\mathrm{AE}$ (Qiagen $\mathrm{GmbH}$ ) and stored at $-20^{\circ} \mathrm{C}$ for use in subsequent experiments.

Bisulfite modification. DNA treatment with bisulfite leads to the deamination of unmethylated cytosines, while leaving methylated cytosines unchanged. The resulting sequence differences from the conversion of deaminated cytosine into uracil and subsequently into thymine make it possible to analyze the methylation patterns of a DNA sequence $(30,31)$. A successful bisulfite alteration depends on essential factors such as similar bisulfite concentration, temperature, clean and entirely denatured DNA, freshly provided bisulfite and a valid $\mathrm{pH}$ status (32). In the present study, DNA extracted from tissue and plasma samples was modified with sodium bisulfite treatment using an EpiTect Fast DNA Bisulfite kit (Qiagen GmbH; cat. no. 59826) according to the manufacturer's instructions. 
Table I. Demographic features of patients group with colorectal cancer and control group.

Demographic features

\begin{tabular}{lcccccr}
\cline { 2 - 3 } Groups & \multicolumn{2}{c}{ Age (years) } & & \multicolumn{2}{c}{ Gender } & P-value \\
\cline { 2 - 3 } & Mean \pm standard deviation & P-value & & Male & Female & $0.594^{\mathrm{b}}$ \\
Patient group $(\mathrm{n}=37)$ & $55.97 \pm 12.63$ & $0.992^{\mathrm{a}}$ & & $15(40.5 \%)$ & $22(59.5 \%)$ & \\
Healthy control group $(\mathrm{n}=37)$ & $55.94 \pm 11.84$ & $15(40.5 \%)$ & & $22(59.5 \%)$ & & \\
\hline
\end{tabular}

Statistical analysis was performed using ${ }^{\mathrm{a}} \chi^{2}$ Fisher's exact two-tailed test and ${ }^{\mathrm{b}} \chi^{2}$ Fisher's exact one-tailed test.

The reaction consisted of bisulfite mix and DNA protection buffer from the kit, in addition to $500 \mathrm{ng}$ template and distilled water to make a total volume of $140 \mu \mathrm{l}$. The bisulfite treatment was performed using an Applied Biosystem VeritiThermal Cycler (Applied Biosystems; Thermo Fisher Scientific, Inc., Waltham, MA, USA) with the following thermocycling conditions: Initial denaturation step at $95^{\circ} \mathrm{C}$ for $5 \mathrm{~min}$; incubation $60^{\circ} \mathrm{C}$ for $15 \mathrm{~min}$; second denaturation step at $95^{\circ} \mathrm{C}$ for $5 \mathrm{~min}$; incubation $60^{\circ} \mathrm{C}$ for $15 \mathrm{~min}$; and hold at $20^{\circ} \mathrm{C}$ for $10 \mathrm{~min}$. The procedure included the following steps: Preparation of DNA from the sample; bisulfite-mediated conversion of unmethylated cytosines (bisulfite thermocycling program); binding of the converted single-stranded DNA to the membrane of a MinElute DNA spin column; washing with wash buffer (Qiagen $\mathrm{GmbH}$ ); sulfonation of membrane-bound DNA; washing with desulfonation buffer (Qiagen $\mathrm{GmbH}$ ) of the membrane-bound DNA to remove the sulfonation agent; and elution of the pure converted DNA from the spin column. A poly-A carrier RNA was added to improve binding of small quantities of DNA to the spin column membrane. Following bisulfite treatment, the quality and quantity of DNA were evaluated by the aforementioned protocol. Purified DNA was eluted in buffer AE and stored at $-20^{\circ} \mathrm{C}$ for use in subsequent experiments.

MethyLight method. In the present study, the MethyLight assay was carried out using two primers and a TaqMan probe, which were specifically annealed to the fully methylated DNA at gene of interest and one assay was carried out using two primers and a TaqMan probe, which were specifically annealed to ALU-C4, a consensus DNA sequence as reference gene for normalization. The MethyLight method can be used in DNA methylation analysis, to detect methylated DNA sequences in presence of the unmethylated DNA $(33,34)$.

Primer and probe design. The primers and probes were designed using Beacon Designer ${ }^{\mathrm{TM}}$ (version 8.13; www .premierbiosoft.com/molecular_beacons; Premier Biosoft International, Palo Alto, CA, USA). The primers and probes were designed to specifically amplify fully methylated bisulfite-converted DNA, a region within the promoter $\mathrm{CpG}$ island in the gene of interest, at the vicinity of the annotated transcription start site provided by the University of California Santa Cruz Genome Browser (genome.ucsc.edu) and the Eukaryotic Promoter Database (EPD; epd.vital-it.ch/human/human_database.php). EPD is an annotated non-redundant collection of eukaryotic POL II promoters for which the transcription start
Table II. Primer and probe sequences used for MethyLight polymerase chain reaction.

Primers and probes

Sequence (5'-3')

SPG20

Forward primer

Reverse primer AAGACGC-3'

Probe 5'-ACCTCGCTCCCGCCACA AAA-3' 6FAM 5'-CAACACGCCGCCGCC GCAACCTAA-3'TAMRA

\section{ALU-C4}

Forward primer

Reverse primer

Probe

$$
\begin{aligned}
& \text { 5'-GGTTAGGTATAGTGGTTT } \\
& \text { ATATTTGTAATTTTAGTA-3' } \\
& \text { 5'-ATTAACTAAACTAATCTT } \\
& \text { AAACTCCTAACCTCA-3' } \\
& \text { 6FAM 5'-CCTACCTTAACCT } \\
& \text { CCC-3'TAMRA }
\end{aligned}
$$

site has been determined experimentally. The MethyLight assay exhibited an amplicon of 94 bp (deposited at GenBank; accession no. NM 015087). The software designed primers with a melting temperature $\left(\mathrm{T}_{\mathrm{m}}\right)$ of $61.8-62.8^{\circ} \mathrm{C}$ and probes with a $\mathrm{T}_{\mathrm{m}}$ of $71.4^{\circ} \mathrm{C}$ for SPG20 gene promoter sequence. In the MethyLight assay, ALU-C4, a consensus DNA sequence, was used as a reference gene and an Alu-based MethyLight control reaction was designed to normalize input DNA. The primers and probes used in the present study were according to those previously reported for ALU-C4 sequences as a reference gene (illustrated in Table II). The primers and probes to the ALU-C4 reference gene were used to bind a bisulfite-converted DNA region of the sequence independently of its methylation status and lack of any $\mathrm{CpG}$ in this region; the amplicon size was 98 bp (35). The ALU-C4 reaction has previously been demonstrated to be less susceptible to normalization errors caused by cancer-associated aneuploidy and copy number changes, compared with the single-copy genes that previously applied in another study $(34,36)$. All primers and probes sequences used in the present study are illustrated in Table II. All primers and probes were purchased from and underwent high performance liquid chromatography purification at Metabion (Steinkirchen, Germany). 
MethyLight quantitative polymerase chain reaction ( $q P C R)$. The qPCR reactions were performed in 96-well plates on a 7500 Real-Time PCR system (Applied Biosystems; Thermo Fisher Scientific, Inc.), using the EpiTect ${ }^{\circledR}$ MethyLight PCR + ROX Vial kit (Qiagen GmbH; cat. no. 59496) according to the manufacturer's protocol. The reactions were performed in a volume of $20 \mu \mathrm{l}$ that included: $2 \mathrm{X}$ EpiTect MethyLight Master mix (without ROX) $10 \mu \mathrm{l}$ containing (HotStarTaq Plus DNA Polymerase, EpiTect Probe PCR buffer, deoxyadenosine triphosphate, deoxycytidine triphosphate, deoxyguanosine triphosphate and thymidine triphosphate of ultrapure quality); $2 \mu 1$ 10X primer-probe mix containing $200 \mathrm{nM}$ probe and $400 \mathrm{nM}$ forward and reverse primers; $0.4 \mu 1$ 50X ROX Dye Solution (passive reference dye for normalization of fluorescent signals); $2 \mu 1$ (20 ng) bisulfite-treated DNA template; and 5.6 $\mu \mathrm{l}$ RNase-free water. Cycle conditions were as follows: Initial PCR activation step at $95^{\circ} \mathrm{C}$ for $5 \mathrm{~min}, 50$ cycles at $95^{\circ} \mathrm{C}$ for $15 \mathrm{sec}$ (denaturation step) and $60^{\circ} \mathrm{C}$ for $1 \mathrm{~min}$ (combined annealing/extension step with fluorescence data collection). Each plate included standard curves for the SPG20 and ALU-C4 sequence, DNA samples, a methylated human bisulfite-converted DNA (EpiTect PCR Control DNA; cat. no. 59655; Qiagen $\mathrm{GmbH}$ ) as a positive control, unmethylated human bisulfite-converted DNA (EpiTect PCR Control DNA; cat. no. 59665; Qiagen $\mathrm{GmbH}$ ) as a negative control, unconverted human genomic DNA from healthy human blood samples, which was not amplified, and a no template control, including the entire ingredients of the reaction except the template DNA. The standard curve was plotted using the Cq value $(13,14,18,19,34,37)$ of the methylated human bisulfite-converted DNA at various concentrations vs. the log value of input DNA concentration. An acceptable MethyLight PCR result was obtained, and is demonstrated by the PCR efficiency (96-102\%), correct slope value $(-3.65--3.2)$ and $R_{2}=0.9985$. In addition, to establish the standard curve, commercial methylated human bisulfite-converted DNA (EpiTect PCR Control DNA; cat. no. 59655; Qiagen $\mathrm{GmbH}$ ) was used as a fully methylated control to calculate the percentage of methylated reference (PMR) of the samples. PMR is the degree of methylation of each sample relative to the fully methylated control.

Chemiluminescence immunoassay. All of the plasma samples were measured to assess the CEA concentration using a Liaison ${ }^{\circledR}$ chemiluminescence analyzer with supporting reagents (Diasorin, Saluggia, Italy). The quantitative determination of CEA in plasma samples was performed using the Liaison CEA kit (cat. no. 314311; Diasorin) according to the manufacturer's protocol.

Statistical analysis. The qPCR MethyLight PCR data were analyzed using software from ABI 7500 SDS version 1.3.1. The level of methylated DNA (the PMR) was calculated for all samples using the following formula: [(SPG20/ALU) sample/(SPG20/ALU) ${ }^{\text {positive control }] \times 100 ~(20,35,38,39) . ~ A ~ s p e c i f i c ~}$ threshold was applied to classify the samples as positive (threshold $\leq$ PMR) or negative (threshold $>$ PMR) methylation status. The optimal cut off point was the highest PMR value obtained from healthy samples (17).

Statistical data analysis was carried out using SPSS software (version 16.0; SPSS, Inc., Chicago, IL, USA). Fisher's exact test and Pearson's $\chi^{2}$ test were used to measure the association between clinicopathological characteristics and classified variables. Where appropriate, Mann-Whitney U test, independent samples t-test and one-way (by Tukey test) analysis of variance were used to compare categorical and continuous variables. $\mathrm{P}<0.05$ was considered to indicate a statistically significant difference. A Receiver Operating Characteristics (ROC) curve was generated using PMR values. The percentile of the highest PMR value across all adjacent healthy tissues or healthy plasma samples were used as a cut-off point of PMR in tissue and plasma samples, respectively.

\section{Results}

DNA methylation of plasma samples. To identify potential DNA methylation biomarkers that are appropriate for the detection of CRC, SPG20 promoter-methylated DNA was investigated in plasma and tissue samples using the MethyLight method. As illustrated in Table III, plasma specimens from patients with CRC and the healthy control group exhibited median PMR values of 7.7 (95\% CI, 4.15-15.28) and 0.59 (95\% CI, 0.14-1.12), respectively. The highest PMR value obtained from the healthy plasma samples was considered as the threshold of methylation status; samples with a PMR $>3.52$ were considered to be positive. Based on this threshold, 30/37 (81.1\%) patient's plasma samples exhibited a positive methylation status. The PMR values were significantly higher in plasma samples from patients with CRC, as compared with those from control subjects $(\mathrm{P}<0.05)$. No significant differences were identified in the frequency of SPG20 hypermethylation status (positive or negative) in plasma samples from patients with CRC according to tumor type, size and location, histological grade of differentiation (29), age, and gender (Table IV). Using the ROC curve, the AUC was identified as 0.984 in plasma samples, exhibiting a sensitivity of $81.1 \%$ and specificity of $96.9 \%$ (Fig. 1).

DNA methylation of tissue samples. As depicted in Table III, median PMR values of 42.39 (95\% CI, 27.69-72.26) and 3.61 (95\% CI, 1.07-5.29) were identified in tumor and adjacent healthy tissues, respectively (Fig. 2). The highest PMR value obtained from adjacent healthy tissues was considered to be the threshold; samples with a PMR $>11.5$ were interpreted to be positive for methylation status. Based on this threshold, positive methylation status was detected in 30/32 tumor tissue samples (93.8\%). As illustrated in Table III, the PMR value was significantly higher in the tumor tissues compared with in the adjacent healthy tissues $(\mathrm{P}<0.05)$. Tissue samples exhibited an AUC of 0.996, representing a sensitivity of $93.8 \%$ and specificity of $99.96 \%$ for this methylation marker. Results from PMR values indicate that there is no statistically significant association between the tissue and plasma samples from patients with CRC and the clinicopathological characteristics (Table V).

CEA of plasma samples. The performance of the CEA tumor marker was compared with PMR values derived from plasma samples. Median CEA levels were demonstrated to be 4.83 (95\% CI, 2.1-9.16) and 1.24 (95\% CI, 0.63-2.84) in samples from patients with $\mathrm{CRC}$ and the healthy control group, respectively. 
Table III. SPG20 gene PMR value of plasma, tissue samples and plasma level of CEA in patients with CRC and in the control group.

\begin{tabular}{|c|c|c|c|c|c|c|c|}
\hline \multirow[b]{2}{*}{ Parameter } & \multirow[b]{2}{*}{ No. of patients } & \multirow[b]{2}{*}{ Minimum } & \multirow[b]{2}{*}{ Maximum } & \multicolumn{3}{|c|}{ Percentiles } & \multirow[b]{2}{*}{ P-value } \\
\hline & & & & 25 th & 50th & 75th & \\
\hline Tissue PMR & & & & & & & $<0.05^{\mathrm{a}}$ \\
\hline Tumor & 32 & 8.61 & 95.81 & 27.69 & 42.39 & 72.26 & \\
\hline Healthy adjacent & 32 & 0.01 & 11.5 & 0.07 & 2.97 & 5.29 & \\
\hline Plasma PMR & & & & & & & $<0.05^{\mathrm{a}}$ \\
\hline Patient & 37 & 1.1 & 36.49 & 4.15 & 7.70 & 15.2 & \\
\hline Control & 37 & 0.01 & 3.52 & 0.14 & 0.59 & 1.12 & \\
\hline Plasma CEA & & & & & & & $<0.05^{\mathrm{a}}$ \\
\hline Patient & 37 & 0.45 & 72.10 & 2.10 & 4.80 & 9.16 & \\
\hline Control & 37 & 0.34 & 4.87 & 0.63 & 0.99 & 2.84 & \\
\hline
\end{tabular}

${ }^{\mathrm{a}} \mathrm{P}<0.05$. Statistical analysis was performed using Mann-Whitney U two-tailed tests. PMR, percentage of methylated reference; CEA, carcinoembryonic antigen; CRC, colorectal cancer.

Table IV. Frequency of SPG20 hypermethylation status in plasma DNA of patients with CRC and clinicopathological parameters.

\begin{tabular}{|c|c|c|c|c|}
\hline \multirow[b]{2}{*}{ Clinicopathological characteristic } & \multirow[b]{2}{*}{ No. of patients } & \multicolumn{2}{|c|}{ Hypermethylation status in plasma } & \multirow[b]{2}{*}{ P-value } \\
\hline & & Positive (\%) & Negative (\%) & \\
\hline Age & & & & 0.339 \\
\hline$<50$ years & 11 & 8/11 (72.7) & $3 / 11(22.3)$ & \\
\hline$>50$ years & 26 & 22/26 (84.6) & $4 / 26(15.4)$ & \\
\hline Gender & & & & 0.283 \\
\hline Female & 22 & 18/22 (81.8) & $4 / 22(18.2)$ & \\
\hline Male & 15 & $12 / 15(80)$ & $3 / 15(20)$ & \\
\hline Tumor type & & & & 0.330 \\
\hline Adenocarcinoma & 21 & 18/21 (85.7) & 3/21 (14.3) & \\
\hline Mucinous & 11 & 9/11 (81.8) & 2/11 (18.2) & \\
\hline Histological grade of differentiation & & & & 0.672 \\
\hline Poorly & 7 & 6/7 (85.7) & 1/7 (14.3) & \\
\hline Moderately & 9 & 8/9 (88.9) & 1/9 (11.1) & \\
\hline Well & 16 & $13 / 16(81.2)$ & 3/16 (18.8) & \\
\hline Tumor location & & & & 0.476 \\
\hline Distal & 8 & $7 / 8(87.5)$ & $1 / 8(12.5)$ & \\
\hline Proximal & 24 & 20/24 (83.3) & 4/24 (16.7) & \\
\hline Tumor size & & & & 0.164 \\
\hline$<50 \mathrm{~mm}$ & 13 & 10/13 (76.9) & $3 / 13(23.1)$ & \\
\hline$\geq 50 \mathrm{~mm}$ & 19 & 17/19 (89.4) & 2/19 (10.6) & \\
\hline
\end{tabular}

Statistical analysis was performed using $\chi^{2}$ Fisher's exact one-tailed test. CRC, colorectal cancer.

\section{Discussion}

In the present study, the PMR values for the SPG20 promoter were measured in plasma and tissue samples obtained from patients with CRC, and in plasma samples from healthy individuals. The MethyLight assay was used to determine the methylation status of the samples. Because of its high specificity, sensitivity and reproducibility, the MethyLight assay is able to measure a small volume of a DNA template, making it an ideal tool to effectively quantify DNA methylation in clinical samples $(33,34)$. In the MethyLight assay, ALU-C4, a consensus DNA sequence, was used as a reference 
Table V. Association between PMR value of plasma, tissue samples and plasma level of CEA and clinicopathological characteristics of patients with CRC.

\begin{tabular}{|c|c|c|c|c|c|c|c|}
\hline \multirow[b]{2}{*}{$\begin{array}{l}\text { Clinicopathological } \\
\text { characteristic }\end{array}$} & \multirow[b]{2}{*}{$\begin{array}{l}\text { No. of } \\
\text { patients }\end{array}$} & \multicolumn{2}{|c|}{ Tissue PMR } & \multicolumn{2}{|c|}{ Plasma PMR } & \multicolumn{2}{|c|}{ Plasma CEA } \\
\hline & & $\begin{array}{c}\text { Mean } \pm \text { standard } \\
\text { deviation }\end{array}$ & P-value & $\begin{array}{c}\text { Mean } \pm \text { standard } \\
\text { deviation }\end{array}$ & P-value & $\begin{array}{c}\text { Mean } \pm \text { standard } \\
\text { deviation }\end{array}$ & P-value \\
\hline Tumor type & & & $0.432^{\mathrm{a}}$ & & $0.155^{\mathrm{a}}$ & & $0.161^{\mathrm{a}}$ \\
\hline Adenocarcinoma & 21 & $50.96 \pm 28.2$ & & $12.88 \pm 9.9$ & & $5.43 \pm 5.0$ & \\
\hline Mucinous & 11 & $42.91 \pm 24.0$ & & $8.01 \pm 6.53$ & & $12.18 \pm 20.6$ & \\
\hline $\begin{array}{l}\text { Histological grade of } \\
\text { differentiation }\end{array}$ & & & $0.991^{\mathrm{b}}$ & & $0.144^{\mathrm{b}}$ & & $0.163^{\mathrm{b}}$ \\
\hline Poorly & 7 & $49.32 \pm 33.1$ & & $9.48 \pm 8.3$ & & $3.86 \pm 3.0$ & \\
\hline Moderately & 9 & $47.45 \pm 24.3$ & & $16.30 \pm 12.4$ & & $3.08 \pm 2.3$ & \\
\hline Well & 16 & $45.18 \pm 26.9$ & & $9.1 \pm 6.41$ & & $12.08 \pm 17.1$ & \\
\hline Tumor location & & & $0.799^{\mathrm{a}}$ & & $0.151^{\mathrm{a}}$ & & $0.193^{\mathrm{a}}$ \\
\hline Distal & 8 & $50.35 \pm 25.8$ & & $7.15 \pm 4.0$ & & $16.73 \pm 23.4$ & \\
\hline Proximal & 24 & $47.50 \pm 27.5$ & & $12.56 \pm 10.0$ & & $4.75 \pm 4.1$ & \\
\hline Tumor size & & & $0.645^{\mathrm{a}}$ & & $0.561^{\mathrm{a}}$ & & $0.131^{\mathrm{a}}$ \\
\hline$<50 \mathrm{~mm}$ & 13 & $45.51 \pm 28.7$ & & $10.04 \pm 8.8$ & & $3.58 \pm 2.6$ & \\
\hline$\geq 50 \mathrm{~mm}$ & 19 & $50.06 \pm 25.9$ & & $12.00 \pm 9.4$ & & $10.60 \pm 16.0$ & \\
\hline
\end{tabular}

${ }^{\mathrm{a} I n d e p e n d e n t ~ s a m p l e ~ t-t e s t . ~}{ }^{\mathrm{b}}$ One-way analysis of variance; PMR, percentage of methylated reference; CEA, carcinoembryonic antigen.

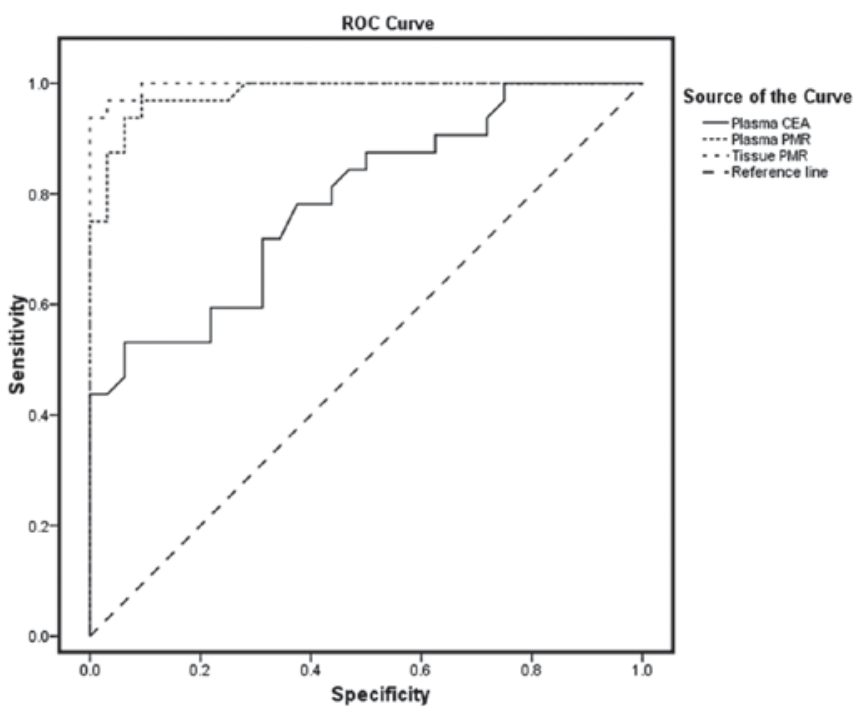

Figure 1. ROC curves for the SPG20 gene PMR value in tissue and plasma samples compared with the plasma CEA tumor marker. ROC, receiver operating characteristic; PMR, percentage of methylated reference; CEA, carcinoembryonic antigen.

gene, demonstrating less local cancer-associated genomic alteration compared with single-copy genes such as $\beta$-actin, GAPDH, myogenic differentiation 1 and collagen type II $\alpha 1$ chain $(34,36)$. The PMR values in plasma samples from patients with CRC were significantly higher compared with samples from healthy individuals. Median PMR values for patients' plasma samples were 12 times higher compared with samples from healthy patients.

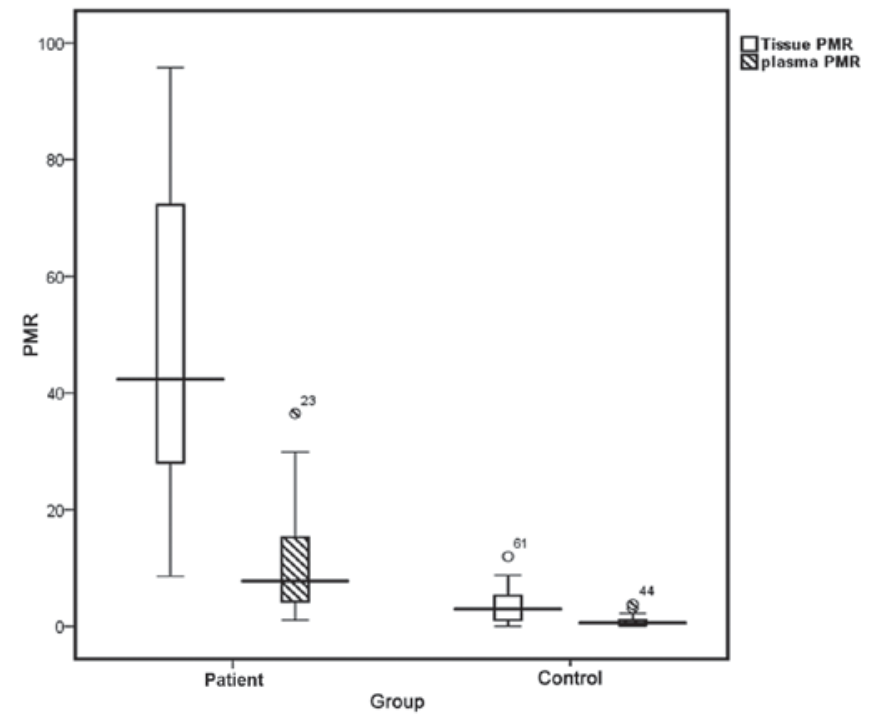

Figure 2. Box plot for PMR value in plasma and tissue samples of patients and the control group. The boxes illustrate the interquartile range, the interval between the 25 th and 75 th percentile. The lines inner the boxes represent median values. PMR, percentage of methylated reference.

Results from ROC curve analysis demonstrated that there was a high AUC of 0.984 for plasma samples, indicating a sensitivity of $81.1 \%$ and a specificity of $96.9 \%$ to discriminate carcinoma from normal status. To the best of our knowledge, no studies have previously investigated the methylation status of SPG20 in plasma samples. Thus, the results of the current study were compared with studies performed on other genes. In a previous study by Warren et al (39), septin 9 (SEPT9) 
promoter methylation analysis was performed in 50 plasma samples from patients with CRC and 90 plasma samples from healthy individuals, demonstrating a sensitivity of $90 \%$ and specificity of $88 \%$ with a $12 \%$ false-positive rate for CRC detection. In a previous study, Grutzmann et al (40) analyzed SEPT9 methylation in plasma, representing $72 \%$ sensitivity and $90 \%$ specificity for CRC detection. Kalmar et al (41) applied the PMR threshold value for SEPT9 methylation and reported a sensitivity of $8.3,30.8$ and $88.2 \%$ for plasma derived from healthy subjects, and patients with adenoma and CRC, respectively. Blood-based methylation analysis on numerous genes, including human mutL homolog 1 , helicase-like transcription factor (42) and runt related transcription factor 3 (43), has revealed sensitivities between $34-90 \%$ and specificities between $69-100 \%$ for CRC diagnosis.

In the present study, the tissue sample results demonstrated $93.8 \%$ sensitivity and $96.9 \%$ specificity based on a putative threshold value. A significant difference was identified in the median PMR values of tumor tissues, compared with adjacent healthy tissues. Consistent with a study conducted by Lind et al (18), promoter hypermethylation of SPG20 was analyzed in tumor, adenoma and healthy tissue samples. However, it was revealed that the SPG20 promoter was methylated in 91, 75 and $2 \%$ of the tumor, adenoma and healthy tissue samples, respectively. In addition, an AUC of 0.947 , a sensitivity of $88 \%$ and specificity of $100 \%$ were identified (18). Notably, results from the present study were comparable with those reported by Zhang et al (44), whereby the SPG20 promoter methylated DNA with methyl specific PCR was analyzed in tissue and stool samples from patients with CRC. They demonstrated that there is $85.4 \%$ sensitivity and $96.9 \%$ specificity, and $88 \%$ sensitivity and $100 \%$ specificity in tissue and stool samples, respectively. In the present study, the association between SPG20 methylation status and clinicopathological characteristics of patients with CRC was evaluated. However, no significant association was identified between these characteristics. Lind et al (17) assessed the promoter methylation status of specific genes, including cannabinoid receptor interacting protein 1 (CNRIP1), fibrillin 1 (FBN1), internexin neuronal intermediate filament protein $\alpha$ (INA), mal T-cell differentiation protein (MAL), synuclein $\alpha$ (SNCA) and SPG20, in CRC, adenoma, and healthy mucosa tissue samples. Consistent with the results of the current study, the results indicated that the genes were methylated in tumor (65-94\%), adenoma (35-91\%) and healthy mucosa samples $(0-5 \%)$. In addition, it was reported that no significant difference was identified in the methylation status of these genes with clinicopathological characteristics of patients with CRC (17). Bethge et al (19) assessed CNRIP1, FBN1, INA, MAL, SNCA and SPG20 genes in 97 cancer cell lines, demonstrating that SNCA and SPG20 were methylated in 97 and $92 \%$ of the tumor samples, respectively. In the present study, it was demonstrated that SPG20 methylation exhibited a significantly higher sensitivity (81.1\%) compared with the CEA tumor marker (48.6\%). The preoperative CRC detection rates of CEA were $30-50 \%$ in patients with CRC (45-47).

Currently, colonoscopy is an invasive method used for CRC diagnosis with poor patient compliance. Furthermore, non-invasive methods, including FOBT and CEA exhibit low specificity and sensitivity (48). Therefore, the development of an acceptable diagnostic method with minimal invasiveness, compared with conventional approaches, is required. In contrast to genetic examination that requires multiple parallel assessments to identify the position of a mutation in a desired gene, promoter methylation occurs in a specific sequence of the gene that can be easily examined using a one step-cost effective analysis. In conclusion, the detection of SPG20 gene methylated DNA using the MethyLight method was revealed to be a highly specific and sensitive epigenetic biomarker for CRC. In addition, the promoter methylation status of SPG20 was demonstrated to exhibit satisfactory sensitivity and specificity in plasma samples, indicating the significance of SPG20 methylation as a noninvasive biomarker for CRC. To the best of our knowledge, this is the first study to investigate the promoter methylation status of SPG20, as a biomarker, in CRC plasma samples. However, further studies with larger sample sizes are required in order to evaluate the specific role of SPG20 methylation as a biomarker for CRC in plasma samples.

\section{Acknowledgements}

The present study was part of a $\mathrm{PhD}$ thesis of N.A. Rezvani, which was supported by the Department of Research and Technology at the Hamadan University of Medical Sciences (grant no. 9304101836). The authors would like to thank the staff of the Medical Genetics Laboratory, Reference Laboratory and Kermanshah University of Medical Sciences for their assistance during the present study.

\section{References}

1. Siegel RL, Miller KD and Jemal A: Cancer statistics, 2015. CA Cancer J Clin 65: 5-29, 2015.

2. Pawa N, Arulampalam T and Norton JD: Screening for colorectal cancer: Established and emerging modalities. Nat Rev Gastroenterol Hepatol 8: 711-722, 2011.

3. Ferlay J, Shin HR, Bray F, Forman D, Mathers C and Parkin DM: Estimates of worldwide burden of cancer in 2008: GLOBOCAN 2008. Int J Cancer 127: 2893-2917, 2010.

4. Stigliano V, Sanchez-Mete L, Martayan A and Anti M: Early-onset colorectal cancer: A sporadic or inherited disease? World J Gastroenterol 20: 12420-12430, 2014.

5. Mohebbi M, Nourijelyani K, Mahmoudi M, Moghadaszadeh B, Mohammad K, Zeraati $\mathrm{H}$ and Fotouhi A: Time of occurrence and age distribution of digestive tract cancers in northern Iran. Iranian J Publ Health 37: 8-19, 2008

6. Smith RA, Cokkinides V and Eyre HJ: American cancer society guidelines for the early detection of cancer, 2006. CA Cancer J Clin 56: 11-25; quiz 49-50, 2006.

7. Dawson MA and Kouzarides T: Cancer epigenetics: From mechanism to therapy. Cell 150: 12-27, 2012.

8. Irizarry RA, Ladd-Acosta C, Wen B, Wu Z, Montano C, Onyango P, Cui H, Gabo K, Rongione M, Webster M, et al: The human colon cancer methylome shows similar hypo-and hypermethylation at conserved tissue-specific $\mathrm{CpG}$ island shores. Nat Genet 41: 178-186, 2009.

9. Rakyan VK, Down TA, Balding DJ and Beck S: Epigenome-wide association studies for common human diseases. Nat Rev Genet 12: 529-541, 2011.

10. Chan AO, Broaddus RR, Houlihan PS, Issa JP, Hamilton SR and Rashid A: CpG island methylation in aberrant crypt foci of the colorectum. Am J Pathol 160: 1823-1830, 2002.

11. Fleischhacker $M$ and Schmidt B: Circulating nucleic acids (CNAs) and cancer-a survey. Biochim Biophys Acta 1775: 181-232, 2007.

12. Shirahata A and Hibi K: Serum vimentin methylation as a potential marker for colorectal cancer. Anticancer Res 34: 4121-4125, 2014. 
13. deVos T, Tetzner R, Model F, Weiss G, Schuster M, Distler J, Steiger KV, Grützmann R, Pilarsky C, Habermann JK, et al: Circulating methylated SEPT9 DNA in plasma is a biomarker for colorectal cancer. Clin Chem 55: 1337-1346, 2009.

14. Herbst A, Rahmig K, Stieber P, Philipp A, Jung A, Ofner A, Crispin A, Neumann J, Lamerz R and Kolligs FT: Methylation of NEUROG1 in serum is a sensitive marker for the detection of early colorectal cancer. Am J Gastroenterol 106: 1110-1118, 2011.

15. Lee BB, Lee EJ, Jung EH, Chun HK, Chang DK, Song SY, Park J and Kim DH: Aberrant methylation of APC, MGMT, RASSF2A, and Wif-1 genes in plasma as a biomarker for early detection of colorectal cancer. Clin Cancer Res 15: 6185-6191, 2009.

16. Lind GE, Kleivi K, Meling GI, Teixeira MR, Thiis-Evensen E, Rognum TO and Lothe RA: ADAMTS1, CRABP1, and NR3C1 identified as epigenetically deregulated genes in colorectal tumorigenesis. Cell Oncol 28: 259-272, 2006.

17. Lind GE, Danielsen SA, Ahlquist T, Merok MA, Andresen K, Skotheim RI, Hektoen M, Rognum TO, Meling GI, Hoff G, et al: Identification of an epigenetic biomarker panel with high sensitivity and specificity for colorectal cancer and adenomas. Mol Cancer 10: 85, 2011.

18. Lind GE, Raiborg C,Danielsen SA, Rognum TO, Thiis-EvensenE, Hoff G, Nesbakken A, Stenmark H and Lothe RA: SPG20, a novel biomarker for early detection of colorectal cancer, encodes a regulator of cytokinesis. Oncogene 30: 3967-3978, 2011.

19. Bethge N, Lothe RA, Honne H, Andresen K, Trøen G, Eknæs M, Liestøl K, Holte H, Delabie J, Smeland EB and Lind GE: Colorectal cancer DNA methylation marker panel validated with high performance in Non-Hodgkin lymphoma. Epigenetics 9: 428-436, 2014

20. Bakowska JC, Jupille H, Fatheddin P, Puertollano R and Blackstone $\mathrm{C}$ : Troyer syndrome protein spartin is mono-ubiquitinated and functions in EGF receptor trafficking. Mol Biol Cell 18: 1683-1692, 2007.

21. Eastman SW, Yassaee M and Bieniasz PD: A role for ubiquitin ligases and Spartin/SPG20 in lipid droplet turnover. J Cell Biol 184: 881-894, 2009.

22. Tsang HT, Edwards TL, Wang X, Connell JW, Davies RJ, Durrington HJ, O'Kane CJ, Luzio JP and Reid E: The hereditary spastic paraplegia proteins NIPA1, spastin and spartin are inhibitors of mammalian BMP signalling. Hum Mol Genet 18: 3805-3821, 2009.

23. Hooper C, Puttamadappa SS, Loring Z, Shekhtman A and Bakowska JC: Spartin activates atrophin-1-interacting protein 4 (AIP4) E3 ubiquitin ligase and promotes ubiquitination of adipophilin on lipid droplets. BMC Biol 8: 72, 2010.

24. Ciccarelli FD, Proukakis C, Patel H, Cross H, Azam S, Patton MA, Bork P and Crosby AH: The identification of a conserved domain in both spartin and spastin, mutated in hereditary spastic paraplegia. Genomics 81: 437-441, 2003.

25. Connell JW, Lindon C, Luzio JP and Reid E: Spastin couples microtubule severing to membrane traffic in completion of cytokinesis and secretion. Traffic 10: 42-56, 2009.

26. Sagona AP and Stenmark H: Cytokinesis and cancer. FEBS Lett 584: 2652-2661, 2010.

27. Heresbach D, Manfredi S, D'Halluin PN, Bretagne JF and Branger B: Review in depth and meta-analysis of controlled trials on colorectal cancer screening by faecal occult blood test. Eur J Gastroenterol Hepatol 18: 427-433, 2006.

28. Lao VV and Grady WM: Epigenetics and colorectal cancer. Nat Rev Gastroenterol Hepatol 8: 686-700, 2011.

29. Reggiani Bonetti L, Barresi V, Bettelli S, Domati F and Palmiere C: Poorly differentiated clusters (PDC) in colorectal cancer: What is and ought to be known. Diagn Pathol 11: 31, 2016.

30. Susan JC, Harrison J, Paul CL and Frommer M: High sensitivity mapping of methylated cytosines. Nucleic Acids Res 22: 2990-2997, 1994.
31. Grunau C, Clark SJ and Rosenthal A: Bisulfite genomic sequencing: Systematic investigation of critical experimental parameters. Nucleic Acids Res 29: E65-E75, 2001.

32. Clark SJ: Studying mammalian DNA methylation: Bisulfite modification. CRC Press, Boca Raton, 2004.

33. Ogino S, Kawasaki T, Brahmandam M, Cantor M, Kirkner GJ, Spiegelman D, Makrigiorgos GM, Weisenberger DJ, Laird PW, Loda $\mathrm{M}$ and Fuchs CS: Precision and performance characteristics of bisulfite conversion and real-time PCR (MethyLight) for quantitative DNA methylation analysis. J Mol Diagn 8: 209-217, 2006.

34. Eads CA, Danenberg KD, Kawakami K, Saltz LB, Blake C, Shibata D, Danenberg PV and Laird PW: MethyLight: A high-throughput assay to measure DNA methylation. Nucleic Acids Res 28: E32, 2000.

35. Weisenberger DJ, Campan M, Long TI, Kim M, Woods C, Fiala E, Ehrlich M and Laird PW: Analysis of repetitive element DNA methylation by MethyLight. Nucleic Acids Res 33: 6823-6836, 2005.

36. Jackson K, Yu MC, Arakawa K, Fiala E, Youn B, Fiegl H, Müller-Holzner E, Widschwendter M and Ehrlich M: DNA hypomethylation is prevalent even in low-grade breast cancers. Cancer Biol Ther 3: 1225-1231, 2004.

37. Pfaffl MW: Quantification strategies in real-time polymerase chain reaction. In: Applied Microbiology. Filion M (ed). Caister Academic Press, Norfolk, UK, pp53-61, 2012.

38. Widschwendter M, Siegmund KD, Müller HM, Fiegl H, Marth C, Müller-Holzner E, Jones PA and Laird PW: Association of breast cancer DNA methylation profiles with hormone receptor status and response to tamoxifen. Cancer Res 64: 3807-3813, 2004.

39. Warren JD, Xiong W, Bunker AM, Vaughn CP, Furtado LV, Roberts WL, Fang JC, Samowitz WS and Heichman KA: Septin 9 methylated DNA is a sensitive and specific blood test for colorectal cancer. BMC Med 9: 133, 2011

40. Grutzmann R, Molnar B, Pilarsky C, Habermann JK, Schlag PM, Saeger HD, Miehlke S, Stolz T, Model F, Roblick UJ, et al: Sensitive detection of colorectal cancer in peripheral blood by septin 9 DNA methylation assay. PLoS One 3: e3759, 2008.

41. Kalmar A, Toth K, Wasserkort R, Sipos F, Wichmann B, Valcz G, Tulassay Z and Molnar B: The detection of methylated Septin 9 in tissue and plasma of colorectal neoplasia and its relationship to the amount of free circulating DNA. Cancer Res 74: 1850-1850, 2014.

42. Leung WK, To KF, Man EP, Chan MW, Bai AH, Hui AJ, Chan FK and Sung JJ: Quantitative detection of promoter hypermethylation in multiple genes in the serum of patients with colorectal cancer. Am J Gastroenterol 100: 2274-2279, 2005.

43. Tan SH, Ida H, Lau QC, Goh BC, Chieng WS, Loh M and Ito Y: Detection of promoter hypermethylation in serum samples of cancer patients by methylation-specific polymerase chain reaction for tumour suppressor genes including RUNX3. Oncol Rep 18: 1225-1230, 2007

44. Zhang H, Song YC and Dang CX: Detection of hypermethylated spastic paraplegia-20 in stool samples of patients with colorectal cancer. Int J Med Sci 10: 230-234, 2013.

45. Yamashita $\mathrm{K}$ and Watanabe M: Clinical significance of tumor markers and an emerging perspective on colorectal cancer. Cancer Sci 100: 195-199, 2009.

46. Yamashita K, Waraya M, Kim MS, Sidransky D, Katada N, Sato T, Nakamura T and Watanabe M: Detection of methylated CDO1 in plasma of colorectal cancer; a PCR study. PLoS One 9: e113546, 2014

47. Zhang SY, Lin M and Zhang HB: Diagnostic value of carcinoembryonic antigen and carcinoma antigen 19-9 for colorectal carcinoma. Int J Clin Exp Pathol 8: 9404-9409, 2015.

48. Koga Y, Yamazaki N and Matsumura Y: Fecal biomarker for colorectal cancer diagnosis. Rinsho Byori 63: 361-368, 2015 (In Japanese). 